\title{
PIRIFORMIS SYNDROME
}

\section{Aggarwal Pawan Kumar *, Agarwal Nidhi.}

Assistant Professor, Maharaja Agrasen College of Physiotherapy, Agroha District Hisar (India).

\section{ABSTRACT}

Piriformis syndrome is a clinical condition of non-discogenic sciatica caused by compression of the sciatic nerve by the piriformis muscle and its patho-physiology is not fully understood. It has variable etiologies. The major etiology known includes spasm, edema and inflammation of the piriformis muscle, and sciatic nerve compression by the muscle later on. Patients can be diagnosed immediately with a comprehensive clinical examination and early diagnosis which makes the treatment much easier. A case of piriformis syndrome diagnosed in a patient who presented with radicular low back pain is reported in this study. Differential diagnosis of the piriformis syndrome, a very rare cause of low back pain, should be thoroughly made with the exclusion of other conditions.

KEY WORDS: Piriform muscle, Piriformis syndrome, Sciatica, Non-Discogenic Sciatica, Radiculer Back pain.

Address for correspondence: Dr. Aggarwal Pawan Kumar, PT., Assistant Professor, Maharaja Agrasen College of Physiotherapy, Agroha District Hisar (India).

E-Mail: drpawanaggarwal@yahoo.co.in

\begin{tabular}{|l|l|}
\hline \multicolumn{3}{|c|}{ Access this Article online } \\
\hline Quick Response code & International Journal of Physiotherapy and Research \\
ISSN 2321- 1822
\end{tabular}

\section{INTRODUCTION}

Piriformis Syndrome (PS) is a neuromuscular disorder caused by the sciatic nerve becoming compressed in the infrapiriformis (sub-pyramidal) canal and occasioning sciatic-type pain, tingling, and numbness in the buttocks along the sciatic nerve pathway down to the lower thigh and into the leg [1-6]. PS is probably an underestimated entity [7] \& the main difficulty in establishing diagnosis is the lack of standard protocol [6-15]. Little is known about PS from an anatomical, biomechanical and clinical view point and its diagnosis is accepted only after other causes of pain arising in the buttocks or lower limbs have been eliminated. Thus, it is a diagnosis of exclusion [6].

PS occurs most frequently during the fourth and fifth decades of life and affects individuals of all occupations and activity levels $[9,10,16-20]$.
PS is more common in women than men, possibly because of biomechanics associated with the wider quadriceps femoris muscle angle (ie, " $\mathrm{Q}$ angle") in the os coxae (pelvis) of women [18-21]. The prevalence of PS in patients with low back pain has been reported to vary widely from $0.33 \%$ to $36 \%$ [19-24]. It may be the reason that difficulties arise in accurately determining the true prevalence of PS because it is frequently confused with other conditions.

\section{CASE REPORT}

A 50 year male came in outpatient department with the complaint of pain over the right gluteal region. Patient had sudden onset of pain since last week before that he was apparently all right. Patient has prolonged standing and sitting work .There is history of long \& excessive traveling in last 10 days. Pain aggravates on sleeping and sitting for more than half an hour and also had 
sleep disturbance due to pain, early morning pain and stiffness also persists. Pain relives on standing and walking after $20-30$ minutes. The patient belongs to good socioeconomic status, having Endomorphic body build, regular smoker since 25 years and presently not having any other problem.

On physical examination Patient has limp while walking, full \& pain free lumbar Ranges in Standing while hip internal rotation is painful. Special tests were within normal limits for PIVD (SLR, Lesigues, Dermatomal and myotomal Patterns ), SI strain ( FABER, Pumphandle, Gaslen's test and strok's tests), with Pain only on Hip resisted external rotation and passive hip internal rotation. There was tenderness on deep palpation in the right gluteal region.

Blood examination reveled normal TLC, DLC, $\mathrm{Hb}$, CRP and ESR Levels. On radiological examination, X-ray LS spine (AP \& Lateral) showed mild space reduction at level of L4-L5 \& L5-S1, mild osteophytes over vertebral body reason with mild spondylotic changes where as MRI was suggestive of disc prolapsed at L4-L5 level but there was no root and spinal nerve compression. However, sacroiliac joints was observed to be normal but there was an asymmetric increase in the size of the right piriformis muscle of the patient compared to the left.

Physical examination was again done keeping in mind the above findings. The observations included localized pain when pressure is applied over the piriformis muscle and its tendon, especially when the hip is flexed at an angle of 90 degrees and the knee is extended i.e. Lasègue sign, Freiberg Sign (pain experienced during passive internal rotation of the hip), Pace sign (consists of pain and weakness by resisted abduction and external rotation of the hip in a sitting position). Pace sign revealed with the FAIR test (flexion, adduction, and internal rotation) involves the recreation of sciatic symptoms. The FAIR test is performed with the patient in a lateral recumbent position, with the affected side up, the hip flexed to an angle of 60 degrees, and the knee flexed to an angle of 60 degrees to 90 degrees. While stabilizing the hip, the examiner internally rotates and adducts the hip by applying downward pressure to the knee\}.
The patient was diagnosed with PS when the complaint, history, physical examination, and laboratory results were evaluated together. Heating modalities (deep and superficial), electrotherapy (IFC, LASER, Ultra sound), hip abduction and gluteal muscle strengthening exercises and piriformis and hamstring muscles stretching exercises were used, and the treatment was discontinued after the recovery. It is suggested that the PS should be kept in mind as a rare situation, in daily practice, as a non-discogenic reason, besides lumbar discoradiculo pathy, in the differential diagnosis of patients presenting with low back and hip pain.

\section{DISCUSSION}

First described by Freiburg and Vinke in 1934 and later confirmed by researchers such as Robinson and Te Poorten, piriformis syndrome is a neuromuscular condition characterized by low back, hip, buttock and leg pain [1].

The piriformis muscle arises from inside the pelvis, over the sacrum and anterior capsule of the sacroiliac joint. It runs laterally through the sciatic notch to become tendinous and insert on the greater trochanter of the femur. The belly of muscle crosses over the sciatic nerve. In 15 percent of cases it has two bellies and the sciatic nerve runs between the two, or the nerve may have two trunks interdigitating with the two muscle bellies [21]. The piriformis muscle is innervated by branches of the L5, S1 and S2 spinal nerves. The function of the piriformis muscle varies according to the position of the hip (with hip extension- laterally rotates the thigh, while with hip flexion- abducts the thigh). It is an important muscle which contributes in walking and for providing balance and stability [18].

There are two types of PS- primary and secondary. Primary PS has an anatomic cause, such as a split piriformis muscle, split sciatic nerve, or an anomalous sciatic nerve path [8,920]. Secondary PS occurs as a result of a precipitating cause, including macrotrauma, microtrauma, ischemic mass effect, and local ischemia [19,2528]. Among patients with PS, fewer than $15 \%$ of cases have primary causes $[19,23]$. PS is most often caused by macrotrauma to the buttocks, leading to inflammation of soft tissue, muscle spasm, or both, with resulting nerve compres- 
sion $[9,18-20,26,27]$. Microtrauma may result from overuse of the piriformis muscle, such as in long-distance walking or running or by direct compression. An example of this kind of direct compression is "wallet neuritis" (i.e., repetitive trauma from sitting on hard surfaces) [18].

Throughout the physical evaluation of patients, clinicians should maintain a high index of suspicion for PS. Early conservative treatment is the most effective treatment, as noted by Fishman et al [29], who reported that more than $79 \%$ of patients with PS had symptom reduction with use of nonsteroidal anti-inflammatory drugs (NSAIDs), muscle relaxants, ice, and rest. Stretching of the piriformis muscle and strengthening of the abductor and adductor muscles should also be included in patient treatment plans [30]. A manual medicine approach may combine muscle Gebauer's spray, stretch technique, soft tissue, myofascial, muscle energy, and thrust techniques to address all somatic dysfunctions in the patient with PS $[20,23,25,26]$. If the patient does not respond adequately to manual treatment, then acupuncture and trigger point injection with lidocaine hydrochloride, steroids, or botulinum toxin type A (BTX-A) may be considered [23,31-33]. If all the pharmacologic and manual medicine treatments fail, the final treatment option is surgical decompression $[9,18,20,23,24]$.

\section{CONCLUSION}

PS is a complex condition that is often not considered in the differential diagnosis of chronic hip and low back pain. To aid diagnosis, several tests have been developed to reproduce the pain by actively contracting or passively stretching the piriformis muscle and compressing the sciatic nerve. Radiographic studies and neuroelectric tests are primarily used to narrow the differential diagnosis toward PS by ruling out other pathologic conditions. A holistic approach to diagnosis involves a thorough history and physical assessment and examination of the patient, based on the pathologic characteristics of PS. Physiotherapy treatment can be used as one of several possible non pharmacologic therapies for these patients. Non pharmacologic therapies can be used alone or in conjunction with pharmacologic treatments in the manage- ment of PS in an attempt to avoid surgical intervention.

Still there is lack of knowledge regarding PS for optimal patient care. Keeping PS in mind for evaluation of the common complaint of low back pain and reaching an early diagnosis are very important for both physicians and patients. Additional research is needed for patients with PS, primarily concerning causative factors, risk factors, diagnostic criteria and optimal treatment, length of time from symptom onset to initial presentation, and the proportion of patients presenting with low back pain who demonstrate symptoms and signs consistent with PS.

\section{Conflicts of interest: None}

\section{REFERENCES}

[1]. Hopayian K, Song F, Riera R, Sambandan S. The clinical features of the piriformis syndrome: a systematic review. Eur Spine J 2010;19:2095-109.

[2]. Hugues SS, Goldstein MN, Hicks DG, Pellegrini VD. Extrapelvic compression of the sciatic nerve. J Bone Joint Surg Am 1992;74:1553-9.

[3]. Jroundi L, El Quessar A, Chakir N, El Hassani MR, Jiddane $M$. The piriformis syndrome: a rare cause of non-discogenic sciatica. A case report. J Radiol 2003;84:715-7.

[4]. Kirschner JS, Foye PM, Cole JL. Piriformis syndrome, diagnosis and treatment. Muscle Nerve 2009;40:108.

[5]. Michel F, Decavel P, Toussirot E, Tatu L, Aleton E, Monnier $G$, et al. The piriformis muscle syndrome: an exploration of anatomical context, pathophysiological hypotheses and diagnostic criteria. Ann Phys Rehabil Med 2013. http://dx.doi.org/10.1016/ j.rehab.2013.03.006.

[6]. Michel F, Decavel P, Toussirot E, Tatu L, Aleton E, Monnier $G$, et al. The piriformis muscle syndrome: diagnostic criteria and treatment of a monocentric series of 250 patients. Ann Phys Rehabil Med 2013;56:371-383.

[7]. Bard H, Demondion X, Vuillemin V. Entrapment syndromes of gluteal area and lateral side of the hip. Rev Rhum 2007;74:393-400.

[8]. Beauchesne RP, Schutzer SF. Myositis ossificans of the piriformis muscle: an unusual cause of piriformis syndrome. A case report. J Bone Joint Surg Am 1997;79:906-10.

[9]. Benson ER, Schutzer SF. Post-traumatic piriformis syndrome: diagnosis and results of operative treatment. J Bone Joint Surg Am 1999;81:941-9.

[10]. Brown JA, Braun MA, Namey TC. Piriformis syndrome in a 10-year-old boy as a complication of operation with the patient in the sitting position. Neurosurgery 1988;23:117-9. 
[11]. Chantraine A, Gauthier C. Le syndrome du muscle pyramidal. Ann Readapt Med Phys 1990;33:34753.

[12]. Chung TS, Diffily J. Piriformis syndrome: myth or fact? Arch Phys Med Rehabil 1987;68:641.

[13]. Durrani Z. "Sciatic radicular pain" or piriformis muscle syndrome? Anesth analg 1989;69:260.

[14]. Picco AG, Parajua Pozo JL. The piriformis muscle syndrome due to pyomyositis. Med Clin 1993;100:436-7.

[15]. Robinson DR. Piriformis syndrome in relation to sciatic pain. Am J Surg 1947;73:355-8.

[16]. Beaton LE, Anson BJ. The sciatic nerve and the piriformis muscle: their interrelation a possible cause of coccygodynia. J Bone Joint Surg Am. 1938;20:686688. Available at: http://www.ejbjs.org/cgi/reprint/ 20/3/686.Accessed September 9, 2008.

[17]. Beatty RA. The piriformis muscle syndrome: a simple diagnostic maneuver.Neurosurgery. 1994;34:512514.

[18]. Boyajian-O'Neill Lori A.,McClain Rance L., et al. Diagnosis and management of piriformis syndrome: an osteopathic approach. JAOA 2008;108:657-64.

[19]. Foster MR. Piriformis syndrome. Orthopedics. 2002;25:821-825.

[20]. TePoorten BA. The piriformis muscle. J Am Osteopath Assoc. 1969;69:150-160.

[21]. Pace JB, Nagle D: Piriform syndrome. West J Med 124: 435-439, 1976.

[22]. Bernard Jr TN, Kirkaldy-Willis WH: Recognizing specific characteristics of nonspecific low back pain. Clin Orthop 217: 266-280, 1987.

[23]. Papadopoulos EC, Khan SN. Piriformis syndrome and low back pain: a new classification and review of the literature. Orthop Clin North Am. 2004;35:6571.

[24]. Parziale JR, Hudgins TH, Fishman LM: The piriformis syndrome. Am J Orthop 25: 819-823, 1996.

[25]. Chaitow L. Soft Tissue Manipulation: A Practitioner's Guide to the Diagnosis and Treatment of Soft-Tissue Dysfunction and Reflex Activity. 3rd ed.Rochester, Vt: Healing Arts Press; 1988.
[26]. DiGiovanna EL, Schiowitz S, Dowling DJ, eds. An Osteopathic Approach to Diagnosis and Treatment. 3rd ed. Philadelphia, Pa: Lippincott Williams \& Wilkins; 2005.

[27]. Retzlaff EW, Berry AH, Haight AS, Parente PA, Lichty HA, Turner DM, et al. The piriformis muscle syndrome. J Am Osteopath Assoc. 1974;73:799-807.

[28]. Steiner C, Staubs C, Ganon M, Buhlinger C. Piriformis syndrome: pathogenesis, diagnosis, and treatment. J Am Osteopath Assoc. 1987;87:318-323.

[29]. Fishman LM, Dombi GW, Michaelsen C, Ringel S, Rozbruch J, Rosner B, et al. Piriformis syndrome: diagnosis, treatment, and outcome-a 10-year study [review]. Arch Phys Med Rehabil. 2002;83:295-301.

[30]. Prather H. Sacroiliac joint pain: practical management. Clin J Sport Med. 2003;13:252-255.

[31]. Benzon HT, Katz JA, Benzon HA, Iqbal MS. Piriformis syndrome: anatomic considerations, a new injection technique, and a review of the literature. Anesthesiology. 2003;98:1442-1448.

[32]. De Andres J, Cerda-OImedo G, Valia JC, Monsalve V, Lopez-Alarcon, Minguez A. Use of botulinum toxin in the treatment of chronic myofascial pain. Clin J Pain. 2003;19:269-275.

[33]. Magee DJ. Orthopedic Physical Assessment. 3rd ed. Philadelphia, Pa: WB Saunders Co; 1997.

[34]. Pecina M. Contribution to the etiological explanation of the piriformis syndrome. Acta Anat (Basel). 1979;105:181-187.

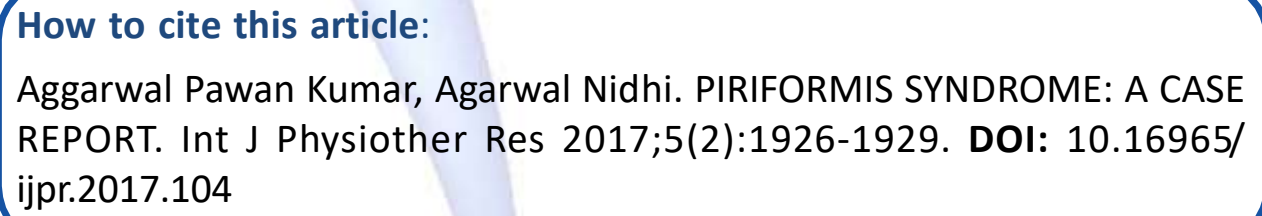

